\title{
Using an extended food metaphor to explain concepts about pedagogy
}

Noeline Wright

The University of Waikato

\section{Abstract}

It is anathema for educators to describe pedagogy as having a recipe - it is tantamount to saying it is a technicist process rather than a professional one requiring active, informed decision-making. But if we are to help novice teachers understand what pedagogy is and how it can be understood, there must be a starting point for pedagogical knowledge to shape both the understanding and design of appropriate curriculum learning. In order to address this challenge, I argue that food preparation processes and learning how to competently cook are analogous to understanding how pedagogy also about process, design, and making knowledge knowable - facilitates learning about teaching specific curriculum knowledge. To do so, I use evidence from an ITE cohort lecture on pedagogy as a case study. In essence, viewing pedagogy through the lens of food and recipes may help make some abstractions of pedagogy more concrete and make some principles of pedagogy more accessible to novice teachers as they learn to design learning.

\section{Introduction}

This introduction sets the scene within Initial Teacher Education (ITE). It outlines the context of the study and issues around finding a starting place for ITE students by canvassing relevant literature, and making a case for the choice of metaphor. It then explores the particular study context in which the extended metaphor was applied.

\section{One-year graduate ITE programmes}

Secondary graduate ITE programmes in New Zealand can be characterised as high intensity within a short time frame. As Wilson and McChesney (2013) argue, preservice teachers "are a unique subset of teachers, because they are at the beginning of their teaching careers and are learning to plan using relatively unfamiliar curriculum materials" (p. 103). In less than a calendar year for many ITE programmes (such as a secondary graduate one-year programme), there is little developmental time for pre-service teachers to increase familiarity with what pedagogy means in curriculum design and practice terms.

It is critically important for novice teachers to understand that "Mere content knowledge is likely to be as useless pedagogically as content-free skill" (Shulman, 1986, p. 8). As a result, it is difficult for preservice teachers in short graduate programmes to fully grapple with the complexities of pedagogy, when they are primarily interested in delivering the subject content they have become passionate about. Broadly speaking, is common for graduates entering the University of Waikato programme to expect that their ITE programme is about learning how to 'deliver' what they know, for conceptions of pedagogy tend to be, at most, nascent, or, as Ryan and Healy (2009) suggest, "naive epistomological beliefs" (p. 424). Thus the shock of discovering that education is a discipline with its own theories and practices involving understanding how learning occurs, and the role of a teacher in fostering that learning, can be profound for some of these beginner teachers. While subject resources and discipline knowledge form part of the "material medica of pedagogy, the pharmacopeia from which the teacher draws those tools of teaching that present or exemplify particular content" 
(Shulman, 1986, p. 10 - original italics), it is pedagogy which helps them know how to make this material medica accessible.

\section{Finding a common starting place}

A starting place for developing ITE students' knowledge about pedagogy is critical, for as Lim and Chan (2007) argue, the pre-service stage is critical for beginning shifting perceptions of pedagogy. A starting place - that is, a place of prior connection, resonates with Vygotsky's (1978) theory about the Zone of Proximal Development (ZPD) since prior knowledge is a key way to add to and grow a learner's conceptual knowledge. As Lakoff and Turner (1989) and Lakoff and Johnson (2003) argue, metaphors are one way of locating and connecting the unknown to the known, for "metaphor is pervasive in everyday life, not just in language but in thought and action" (Lakoff \& Johnson, 2003, p. 4). A metaphor that hooks into prior knowledge therefore, is likely to be highly influential in individuals' abilities to 'see' or 'get' a new concept more easily. Beginning with some kind of common ground upon which to build new understandings is thus crucial if new knowledge is to take hold in the learner. And when pedagogy is at stake, it is important to get right.

However, Lakoff and Johnson (2003) argue that while metaphors are beneficial, they have limitations - they cannot be whole replacements, only partial:
...if ideas are objects, we can dress them up in fancy clothes, juggle them, line them up nice and neat, etc. So when we say that a concept is structured by a metaphor, we mean that it is partially structured and that it can be extended in some ways but not others (p. 14).[italics in original]

In other words, there is a proviso that applies to developing an extended metaphor about pedagogy in relation to food - that it too will have limitations. The extended metaphor is, however, intended to serve as an introduction to conceptual thinking about pedagogy, not the whole idea or whole practice; it is the starting point, because starting is often the hardest step, and for beginning teachers, learning how to interpret curriculum requirements for learners in terms of pedagogical design can pose difficulties.

There are precedents for metaphors that describe aspects of learning. The SOLO Taxonomy (Biggs, n.d.), which uses the visual metaphor of components of a house to illustrate the components of structuring understanding and learning to know, is one of these. Basically, it illustrates the journey from novice to expert in terms of putting pieces of knowledge together through describing the "Structure of the Observed Learning Outcome....as a means of classifying learning outcomes in terms of their complexity, enabling us to assess students' work in terms of its quality not of how many bits of this and of that they got right" (Biggs, n.d.). This is an inspiration for creating a way of understanding how ITE students can develop their conceptual thinking about pedagogy.

Lakoff (1992) argues that "as soon as one gets away from concrete physical experience and starts talking about abstractions or emotions, metaphorical understanding is the norm" (n. p.). In other words, we try to make sense of complex stuff in terms that others might know it too. The conceptual understanding of pedagogy fits this argument. Petrie and Oshlag (1993) for example, argue that "metaphor is one of the central ways of leaping the epistemological chasm, between old knowledge and radically new knowledge" (p. 58), describing the way we hang new knowledge and understanding on to what we already know in order to make the necessary intellectual and knowledge leaps. Those who learn to be teachers also need something to hang their subject content onto, if they are design learning experiences.

In order to frame the concept of pedagogy, food recipes can work as an analogy, for as Jones notes, "Recipes have a clearly defined structure that, once learned, allows you to very quickly create the starting point for an idea" (2014, p. 13). So, for novice teachers, having a sense of what a pedagogical structure might look like and what it means in terms of designing lessons, is likely to be a help rather than a hindrance in addressing specific learning curriculum requirements for learners. The next section explores food as an extended metaphor for pedagogy. An extended metaphor is a literary mechanism authors use to reinforce a key idea, often in poetry and novels. 


\section{Arguing for food as a metaphor}

Food is a common ground/starting point for all learners, since we all eat. With the plethora of cooking shows available on various media, exposure to ideas about cooking are hard to avoid. Food is thus a reasonably safe starting place as a metaphor about pedagogy. It has potential in bridging gaps between curriculum content and designing learning opportunities. Recipes are a kind of pattern, and patterns can be understood as a known organisation of events, structures, chronologies, processes, or methods. Jones (2014) argues that patterns:

...do not rely on typologies or frames in that they can be rich collections of information presented in a particular way - they are in many ways descriptions or narratives of common problems and solutions that emerge from real-world cases (p. 10).

Thus curriculum documents can be described as patterns attempting to explain how specific concepts and associated knowledge are arranged for learning purposes. While Jones explored patterns in terms of research, his ideas resonate with a comparison of pedagogy, patterns and food. Pedagogical design and practice is by its nature not fixed, but necessarily responsive to students' learning needs. There are discernible patterns in the structure and balance between teacher-centric curriculum instruction and student-centric activities in lesson design. Thus, through extending a food metaphor to the specifics of a recipe and the role of a cook, we can "translate elements of information and knowledge" (Jones, 2014, p. 12) - including theories - into more concrete and usable understandings to better understand pedagogy.

Downes' (2014) April 21 blogpost for example, conceptualised theories as answering "whyquestions. They identify underlying causes, influencing factors, and in some cases, laws of nature" (para 7). To some extent, a curriculum document attempts to do that. So finding ways to connect preservice teachers to both theory and practice is very important if they are to engage in evidence-led curriculum practices in schools.

To that end, I have used the overarching idea of food as a metaphor. For example, the extended metaphor includes reference to recipes, food preparation, and the role of the chef/cook to explain pedagogy and the role of a teacher.

It is also important to note that I examine this idea situated as an initial teacher educator teaching within the same ITE programme. I am interested in connecting ITE students with the concept and practice of pedagogy. This means finding a starting place (ZPD). The food metaphor, as the overarching frame of reference, tests this aim.

\section{Applying the food analogy}

The context for implementing the food analogy is a lecture to an entire cohort ( $\mathrm{n}=85$ ), deliberately preceding both a tutorial session and their first six-week practicum. The purpose of the lecture is to remind them of the power and importance of pedagogical design in structuring meaningful learning. This is my only lecture to the entire cohort, even though I teach them all, but in another capacity and in smaller groups at a time.

The lecture of interest is called "Understanding pedagogy through the metaphor of food". In it, I invite the cohort to comment on particular aspects of the lecture via a backchannel 'room' (TodaysMeet). Beforehand, the cohort are asked to bring a wifi-enabled device to class (for those without one, loan devices are available). There are four main purposes in this backchannel:

1. to demonstrate how learners can actively participate and contribute to constructing meaning and thinking about what is taking place

2. to demonstrate how ideas of inclusion and voice can be interpreted and enacted.

3. to give voice to their perspectives and gauge the extent of engagement in the expected learning and thinking processes implied in the lecture design

4. to create data for analysis. 
These purposes are made explicit to the cohort at the start of the lecture, keeping in mind Loughran's (2010) argument that such openness about intent is critical to the development of pedagogical content knowledge. What follows is some of the detail of the lecture to illsutrate how the metaphor is used.

The lecture begins with Bud Blake's strip, I Taught Stripe to Whistle (1974, May 6).The comic strip illustrates in simple terms what the discipline of pedagogy is about: that delivery of content is not linear, nor is it assured in terms of intended outcomes, summed up in the comic strip's final speech bubble saying, "I said I taught him. I didn't say he learned it". This point frames the rationale for the metaphor: that what we think we teach, is not always what is learned. The comic strip infers that the relationship between teaching and learning can be tenuous, which is why careful pedagogical design to interpret curriculum requirements is important for teaching and learning.

Pedagogical design is therefore a crucial step if intended learning has any chance of success. As Mayes and De Freitas (2004) suggest, pedagogical design is about "placing the learning and teaching activities at the heart of the process" (p. 6). The responsibility for teaching does not stop at the delivery of information, but focuses on approaches that help learners develop and internalise new knowledge, skills and understanding. This involves a teacher internalising a deep understanding of learning theories and their practice, in order to precipitate learners' conceptual thinking. As Mayes and De Freita argue, "For good pedagogical design, there is simply no escaping the need to adopt a theory of learning" (2004, p. 6).

This is the rationale for choosing an extended metaphor about food. What follows in Table 1 are components of a recipe and a pedagogical design, showing connections in order to make the latter more tangible to pre-service teachers. The rest of the lecture is spent explaining why these elements are important to pedagogical design, and how novice teachers' own progression to expert teacher might be understood via this extended food metaphor.

\section{Table 1: Recipes and pedagogy}

\begin{tabular}{|c|c|c|}
\hline & RECIPES & PEDAGOGY \\
\hline COMPONENTS & $\begin{array}{l}\text { Recipes: } \\
\text { - } \text { specific ingredients } \\
\text { - } \text { proportions/measurements } \\
\text { - utensils and equipment }\end{array}$ & $\begin{array}{l}\text { Learning: } \\
\begin{array}{l}\text { - } \\
\text { - needudent group and learning } \\
\text { - class facilities } \\
\text { - curriculum concepts } \\
\text { - } \text { content } \\
\text { - thinking processes }\end{array}\end{array}$ \\
\hline $\begin{array}{l}\text { METHODS/ } \\
\text { PROCESSES }\end{array}$ & $\begin{array}{l}\text { How to create the product/the goal of a } \\
\text { recipe (ie, the dish): } \\
\text { the mix/chemistry (knowing } \\
\text { how and why certain processes } \\
\text { affect cooking outcomes) } \\
\text { - technical knowledge of cooking } \\
\text { processes and combinations of } \\
\text { ingredients } \\
\text { cooking times and effective use } \\
\text { of equipment to make the } \\
\text { recipe become good food }\end{array}$ & $\begin{array}{ll}\text { How to aim for a learning/curriculum } \\
\text { goal: } \\
\text { - } \\
\text { the mix/chemistry (knowing } \\
\text { how and why certain } \\
\text { processes affect learning } \\
\text { outcomes) } \\
\text { - } \quad \text { technical knowledge of } \\
\text { learning and facilitation } \\
\text { processes such as: } \\
\text { metacognition, pedagogical } \\
\text { design, timing, order, } \\
\text { opportunity } \\
\text { - } \quad \text { sing resources/equipment for } \\
\text { meeting curriculum learning } \\
\text { goals } \\
\text { specific organisation of } \\
\text { learning to scaffold thinking } \\
\text { and knowing }\end{array}$ \\
\hline
\end{tabular}




\begin{tabular}{|c|c|c|}
\hline CHRONOLOGY & $\begin{array}{l}\text { The order in which food processes } \\
\text { need to happen: } \\
\text { - order and combinations in } \\
\text { mixing of ingredients } \\
\text { - cooking receptacles } \\
\text { - cooking times/cooking order }\end{array}$ & $\begin{array}{l}\text { The order in which learning needs to } \\
\text { happen: } \\
\text { beginning with prior } \\
\text { knowledge } \\
\text { building block/scaffolding } \\
\text { activities and skills to address } \\
\text { prerequisite knowledge } \\
\text { processes (developing } \\
\text { conceptual learning/problem- } \\
\text { solving) }\end{array}$ \\
\hline THE EVIDENCE & $\begin{array}{l}\text { Plating the food: } \\
-\quad \text { how it looks, smells, tastes } \\
-\quad \text { the degree of satisfaction in } \\
\text { eating it } \\
\text { - a sensory and affective experience }\end{array}$ & $\begin{array}{l}\text { The evidence of: } \\
\text { - } \\
\text { (abstraction, inference, } \\
\text { analysis, justification, } \\
\text { synthesis, reflection, } \\
\text { judgement, threshold } \\
\text { concepts) } \\
\text { procedural learning } \\
\text { (understanding of process, } \\
\text { method, order...) } \\
\text { - metacognitive learning - } \\
\text { learning how to } \\
\text { learn/articulating strategies } \\
\text { the satisfaction } \\
\text { ('fun'/enjoyment) in the } \\
\text { challenge/level of } \\
\text { achievement and learning in } \\
\text { the task } \\
\text { - a cognitive and affective } \\
\text { experience }\end{array}$ \\
\hline $\begin{array}{l}\text { EVALUATION } \\
\text { AND } \\
\text { REFLECTION }\end{array}$ & $\begin{array}{l}\text { Feedback on the dish by the diners: } \\
\text { - Look, taste and smell } \\
\text { Satisfaction (fullness, texture, } \\
\text { size, how appetising it is) } \\
\text { Was it worth eating? } \\
\text { Evaluation by cook: } \\
\text { - Is it worth creating again (cost, } \\
\text { time, effort, effect on diners)? } \\
\text { Does it need refinement (what } \\
\text { needs changing - taste, } \\
\text { plating,...?) } \\
\text { - Would different ingredients } \\
\text { work? } \\
\text { with a different combination of } \\
\text { diners, what needs changing } \\
\text { (dietary needs, timing)? }\end{array}$ & $\begin{array}{l}\text { Feedback and behaviours of learners: } \\
\text { Coming back for more when } \\
\text { the learning is successful, } \\
\text { satisfying, challenging } \\
\text { - } \text { evidence of realising it's a } \\
\text { work in progress that includes } \\
\text { risk-taking, feedback and self- } \\
\text { reflection } \\
\text { - deciding if their own learning } \\
\text { intentions/goals have been } \\
\text { achieved... } \\
\text { Teachers: } \\
\text { - have learning goals been } \\
\text { achieved? } \\
\text { does it need } \\
\text { refinement/alteration? } \\
\text { what if different resources } \\
\text { were used? } \\
\text { what was the learner } \\
\text { experience like? } \\
\text { with a different class, how } \\
\text { should it be modified? - } \\
\text { resources, strategies, learning } \\
\text { needs, order... }\end{array}$ \\
\hline
\end{tabular}


Because linking theory to practice is often conceptually difficult for pre-service teachers, Table 1 makes more concrete some of the more abstract elements of pedagogy, since understanding the relationship between theory and practice is a critical part of the pedagogical design puzzle. Doing (action) has often been privileged over knowing (understanding), for the following mantra is often heard: 'give me something I can teach tomorrow'. Developing deep thinking and learning across a range of fields is, however, what education is supposed to be about rather than replicating doing. Education is essentially about making explicit the subterranean foundations of what 'doing' means so that teachers can use effective pedagogical design principles that support learning for specific groups of learners. This is why understanding the teacher's role in facilitating learning rather than delivery, is so important to understand.

This brings me back to food as a metaphor. Understanding deeply what good pedagogical practices look like takes time and practice, just as becoming a competent cook takes time and practice. For example, novice cooks tend to stick closely to what a recipe prescribes because they do not have deep knowledge to draw on that would help them adapt, substitute, or alter the recipe for different contexts or circumstances. For novice teachers, teaching is usually about content and delivery and managing student behaviour. They rely on lesson plans and seldom deviate from it because they lack the experience to adapt, substitute or alter it. A focus on content, delivery and behaviour is also less troublesome than focusing on the less tangible but important aspirations of The New Zealand Curriculum (Ministry of Education, 2007), such as conceptual cognitive processes and social cohesion.

An extended metaphor of food offers access to the deep thinking teachers apply when designing learning to stimulate the deep thinking of their students - what Leslie (2014) calls epistemic curiosity (deep learning) and diversive curiosity (hunger for the new). Epistemic curiosity requires persistence, effort, patience, and a desire to understand something deeply. Take for instance, how we know how to make meringues or cakes, and why meringue or cake recipes are so similar in their processes. Know-how is about both the doing and the why of the doing. Over time, cooks have experimented with different ways of making a meringue or cake. This 'trying out' is a research process, where some cakes or meringues end up better than others, so some processes are replicated while others are discarded. Over time, these processes are both the theory and practice of cake or meringue-making, shared as part of the wisdom of cooking well. Some cooks therefore, were curious enough to think about distilling the patterns of successful cake- or meringue-making and document them. Understanding teaching and learning has a similar trajectory of theorising through trial, error, curiosity, documenting patterns, and sharing this knowing.

\section{Understanding learning to teach through learning to cook}

Bittman (2011) described four stages of learning to cook by characterising cooking behaviours from novice to expert. Stages of learning to teach can be understood similarly, and so Bittman's stages were included in the lecture on pedagogical thinking. Bittman argues that when cooks are novices, a key characteristic is slavishly following recipes, becoming anxious if there are deviations or hiccups, such as not having an ingredient, for such cooks have no capacity to improvise because they don't yet have enough knowledge or experience to know how to plug such a gap. In teaching terms, this might be a new teacher saying something like, "Where's the unit/lesson plan?" Or "tell me what to teach and I'll do it". Such a novice will find it hard to adjust a lesson to the vagaries of the classroom climate or fully understand students' learning needs. Like the novice cook, new teachers will rely on content and managing behaviour, rather than understanding learning processes or drawing on pedagogical content knowledge. When something unexpected happens, they have little capacity to accommodate it.

At stage two however, the cook is developing greater awareness of his or her own preferences, and will start comparing and synthesising elements of recipes, adapting them to suit 
circumstances - but in safe, predictable ways. This might mean substituting a lemon for a lime in a recipe -which is within the boundaries of the known and the safe. A teacher at such a stage might be able to teach the same thing to two classes, and use slightly different resources for each. This teacher recognises that the student groups are different, needing to, perhaps work at different paces have slightly different requirements. This suggests an awakening to learners' needs and what sort of pace suits, but this teacher is still operating within safe boundaries of the tried and true.

A stage three cook, Bittman says, becomes more curious, possibly seeking out more and more cookbooks to learn from and ingredients to experiment with. Such a cook might read cookbooks in bed, rely less and less on specific details in recipes, but be more alert to the processes and theories of cooking methods and products. Such cooks are developing a metacognitive awareness of the field, focusing much more on a diner's experience of the food as well as feeding their own curiosity about trying new foods. A teacher operating at such a stage would be focusing on knowing more about pedagogical processes, developing their Pedagogical Content Knowledge (Shulman, 1986). They are likely to read widely about their curriculum area and ways others teach it, in order to experiment themselves. This teacher will be open to new resources and tools to support learning, and be more focused on what students need as learners. This teacher will strive to find the best mix for designing effective lessons, sharing ideas in the staffroom, and especially among learning area colleagues. They will ask questions, engage in some theorising, wondering and reflecting on their own practices.

Stage four indicates greater maturity and expertise. This cook has a wide repertoire to call on, able to design a dish around ingredients, and, without knowing what the final dish may look like, know what will harmonise for a satisfying eating experience. A wise and experienced teacher is similarly skilled by adapting pedagogical design to meet contextual and student demands, often it seems, effortlessly and at will. And, like a skilled cook, this expert teacher will constantly evaluate their practice by checking for learning and how well things 'taste'. This teacher knows what the learning has to aim for, and is unafraid to experiment with resources, pedagogical strategies and tools. This teacher will also have a good idea of the goals in mind, but will be happy to alter the route if need be. Teachers operating in this expert range will also be secure in their pedagogical content knowledge (often referred to as PCK).

As Wright (2011) noted, experienced teachers (stage four) have greater capacity to undertake experimentation than less experienced teachers. In her mLearning study, all of the participant teachers had at least 10 years' teaching experience. They could "accommodate the "pain of failure" (p. 583) because they had enough pedagogical experience to adjust what they did at a moment's notice. In other words, they were more likely to exhibit a "greater focus on students" (Petit \& Kukulska-Hume, 2007) than perhaps less experienced teachers could. And while these teachers' practices "contradict a commonly asserted belief that 'older' teachers are resistant to technological change" (Wright, 2011, p. 583), their pedagogical strength points instead to the value of experience and accrued pedagogical wisdom, much as a cook develops in being able to abandon the recipes and cook intuitively - perhaps theorising on the run.

Through the analogy of food, it is much easier to see how pedagogy is not an instant fix or a takeaway meal, but instead, a slow-cooked, rich feast that requires some preparation. The metaphor also makes clear that pedagogy, like the creation of good food, is always an experiment in action, and relies on the recipient to judge its value; it can wrong at any minute. New Zealand's Masterchef 2013, for example, described himself as a very "experimental cook" (Devine, Saturday April 12, 2014, p. 5) because it is how he extends himself, saying:

Don't be afraid to try new things. Don't worry if things don't work out. Don't judge yourself too much. Follow what feels right, that's when things go well (p. 5).

If that idea is extended to learning about how to teach and to do it well enough that there is regular, positive impact on learners, then it illustrates something of the complex nature of the relationship between teaching, learning and reflective practice. As Pachler, Bachmair and Cook (2010) and Pachler, Cook and Bachmair (2010) suggest, education is both complex (adj) and a complex (n) that is increasingly mobile. It marks the "fluidity, provisionality and instability" (Pachler, Cook \& Bachmair, 2010, p. 2) of learning. Highly aware, skilled and experienced teachers are more likely to cope with 
such complexity, whether as a noun or verb. Taken together, teaching, learning and reflective practice show that when teaching episodes are consciously and deliberately developed and reflected on, learners are more likely to have a satisfying and academically rewarding experience, deepening their subject-specific conceptual knowledge.

Such deliberate development and reflection led me to examine the value of this lecture to the ITE students' thinking about pedagogy and themselves as teachers, since it is a lecture that has been refined each year. The methods, analysis and findings are addressed next.

\section{Evidence basis and discussion}

With ethics approval, the two methods used to collect data for analysis from the cohort $(n=85)$ were a GoogleForm survey, asking for feedback regarding the value of the concept to their understanding of pedagogy once the lecture was complete, and the text from the TodaysMeet backchannel. In the survey, I asked for a combination of paragraph responses or item selection choices that were either scales or a continuum. For example, one question was "How well did the table comparing pedagogy with a recipe help you understand the components of good pedagogy?" Four options were offered: 'really difficult - made no sense to me' to 'really easy, made perfect sense'. The results of this question indicated that no-one, out of the 46 replies $(n=85)$, thought the table was meaningless or made no connections to their understanding. The highest number of responses indicated that the analogy had merit (24), while 15 believed that it made very good sense to them, choosing the 'really easy, made perfect sense' option. It suggests that the details of the comparison resonated with the majority of the survey respondents.

Another question asked, "I talked about praxis in relation to how we know how to make a meringue through both practice and theory-making. Did that explanation help you make sense of the important link between theory and practice?" Respondents chose one of four points from 'not at all' to 'I get it now'. The metaphor made at least partial sense to 11 respondents, while 24 found it made at least reasonably good sense to them and 9 thought it was a really easy way to understand the concept of praxis. One chose 'not at all'.

A third continuum question sought to know the value of the stages of learning to teach through learning to be a good cook. The question asked: How well did this help you see aspects of your own trajectory as teachers? Responses indicated a positive influence, where respondents felt they could position themselves somewhere in one of the four stages.

As well as the documented data outlined above from the survey, a small number (less than 10) of students made a point of verbally commenting on the value of the lecture as they exited the lecture theatre, mentioning factors such as clarifying theories and concepts they had already been exposed to, but not yet made sense of. This verbal feedback is characterised by statements such as (not verbatim, for they were jotted down after the fact):

- "that made really good sense to me, thank you"

- "I'm so glad you used food- I get it!"

- "I really enjoyed that lecture, thank you"

- that was a great comparison - I teach food - it all made sense.

In one of the paragraph answer questions of the survey, respondents were asked to note what they would say to someone who asked about the point of the lecture. Three comments are selected to represent the flavour of the feedback, saying it:

- “...provided a tangible metaphor for pedagogy, so was valuable for me to remember these theories"

- "Provides clarity and structure to the ideas and knowledge we have been forming to date. Helped put the concepts in place"

- "I was able to develop a clearer, more succinct understanding of designing learning and pedagogical approaches as a result of a very interactive lecture." 
However, at least one respondent was almost entirely negative, noting that the lecture was irrelevant on almost all counts. Comments from this person included: "I honestly didn't take much in other than the first slide and the video clips" and "The lecture was probably at the wrong time of the day and week for me...because it wasn't interactive I was not engaged and only really listened to the $2 \mathrm{x}$ video's" (sic), yet did not choose 1 (the least satisfactory) for any of the 4-point scale items. The "not interactive' comment was a surprise, since the backchannel provided ample opportunity for everyone to contribute, remarked on by 30 of the 46 survey respondents. It also featured in verbal feedback. I highlight this set of 'outlier' comments because it shows that we are seldom successful at reaching all our learners all the time, including attempts at defining a common starting place such as food. As the Bub Blake comic strip iterated, there is no certainty that desired learning will occur.

In the survey, one person remarked on having "done" metaphors already and saw no point in revisiting it. Perhaps this indicates something of the way in which compartmentalised learning to tick off loses sight of how deep learning happens, which is an effect of iterative and recursive exposure to ideas and concepts across various scenarios and contexts over time. Perhaps this pre-service teacher is operating at stage one of Bittman's (2011) continuum, not yet connecting learning processes with understanding content. Perhaps too this comment highlights what Loughran (2010) argued that until a teacher has some experience teaching, the experience of teaching has only ever been uni-directional from the perspective of a student rather than a teacher.

As learners in schools and, perhaps in universities, our students are not always privy to the thinking and preparation underpinning a teacher's practices. This takes time to understand, as well as repeated exposure to ideas and experiences. Instead, they see is what happens in the here and now of classroom learning, seeing the surface, not the depth. Knowing and doing, Loughran (2010) argues, are not always understood as being different. So, for someone to remark that they have 'done' metaphors, suggests a lack of understanding yet about the recursive nature of teaching and the importance of revisiting the known in order to access the not known.

Overall, responses through both the backchannel and the survey reflect Lakoff's (1992) idea of metaphor relating to thought. Lakoff discusses a relationship between metaphor and conceptual ideas in terms of one mental domain and its links to another. However, backchannel responses to the food and pedagogy metaphor context provided more clues to how the cohort reacted to the content and concepts of the lecture. They were encouraged, through the posing of open questions as various points of the lecture, to add their perspectives, engaging in conversation around the ideas.

The subsequent tutorial (which other lecturers took in smaller groups) provided further opportunities for the ITE students to examine their thinking in relation to those ideas, hopefully adding to their mental models as they linked mental domains. However, what happened in those tutorials and what has happened subsequently on practicum, is largely unknown for no data were gathered from those contexts. It is a yawning chasm in this attempt to examine what any impact on thinking about pedagogy and curriculum design might be, particularly over a longer term than the moment of the lecture, and thus, along with the time-span of evidence gathering, is a limitation of this small study. It is moot how generalisable the findings are, but they may yet resonate with ITE educators in different contexts.

Addressing this disconnect between the lecture and any long-term impact requires a different sort of project to better understand any effects on preservice teachers' pedagogical thinking as they apply their knowledge to designing learning when they leave their ITE programme. It also requires interviews to probe pre-service/beginning teachers' thinking about pedagogy, preferably at two stages - when they start their ITE programme, and when they leave. And yet, given the hurly-burly of the single year these pre-service teachers have for this programme, inserting and exerting yet more pressure on this cohort may be counter-productive. Perhaps a project tracking teachers in their first three years might succeed in making good sense of how well notions of pedagogy as a 'recipe' have traction in their thinking and practices. Then we might make a robust case for metaphorical understandings that deeply influence pedagogical and curriculum practice. As Shulman (1986) argues, "Case knowledge is knowledge of specific, well-documented, and richly described events" (p. 11) that link theory and practice. This link is what initial teacher education must constantly aim for. 


\section{Conclusion}

The intention of this article was to argue a case for suggesting pedagogy could begin to be explained via the extended metaphor of food, recipes and becoming a competent cook. It could help ITE students better grasp the concept of pedagogy and the role of the teacher by hooking into common prior knowledge and modelling how ZPD can be explicitly leveraged. Through explaining the conceit of the extended metaphor as a starting place for thinking about pedagogy, it may be useful for other teacher educators to use and trial its applicability in different contexts. Notwithstanding the limitations of the evidence and context addressed here, I argue it is important to find ways (such as extended metaphors) to make inroads into ITE students' thinking about what pedagogy is. The postscript indicates something of the food metaphor's potential in this regard:

Postscript: In a later lesson with some of this cohort (about 3 months later and after their first practicum), I informally asked if my pedagogy lecture had any longer-term effect on their thinking. Those present argued that the 4 stages of becoming a competent cook as a metaphor for understanding their trajectory as teachers was very reassuring: they could see that this 4 stages was a long term evolutionary process and reduced their anxiety about not yet fully knowing about being a competent teacher.

\section{Reference list}

Biggs, J. (n.d.). SOLO Taxonomy. Retrieved April 15, 2014, from http://www.johnbiggs.com.au/academic/solo-taxonomy/

Bittman, M. (2011). Finding myself in the kitchen. In, John Donohue, Man with a Pan: Culinary adventures of fathers who cook for their families. (pp. 91-100). Chapel Hill, NC: Algonquin Books of Chapel Hill.

Devine, D. (Saturday April 12, 2014). Cooking with gas. Waikato Times, Your Weekend, p. 5.

Downes, S. (April 21, 2014). Half an Hour. Retrieved May 01, 2014, from http://halfanhour.blogspot.nl/2014/04/connectivism-as-learning-theory.html?m=1

Jones, D. (2014). Why Recipes?: Introduction. In, Alison Williams, Derek Jones and Judy Robertson (Eds). BITE: Recipes for Remarkable Research. S.l.: Sense. Open Access eBook: https://www.sensepublishers.com/catalogs/bookseries/other-books/bite/

Lakoff, G. (1992). The contemporary theory of metaphor. In, Andrew Ortony (Ed.). Metaphor and Thought (2nd edition). Cambridge UK: Cambridge University Press. Retrieved from: http://terpconnect.umd.edu/ israel/lakoff-ConTheorMetaphor.pdf

Lakoff, G., \& Turner, M. (1989) More Than Cool Reason: A Field Guide to Poetic Metaphor. Chicago: University of Chicago Press

Lakoff, G., \& Johnson, M. (2003) Metaphors We Live By. Chicago: University of Chicago Press.

Lim, C. P., \& Chan, B. C. (2007). microLESSONS in teacher education: Examining pre-service teachers' pedagogical beliefs. Computers and Education. 48(3) 474-494 doi:10.1016/j.compedu.2005.03.005

Leslie, I. (2014). Curious: The desire to know \& why your future depends on it. London: Quercus Editions. ISBN (ebook) 9781782064961

Loughran, J. J. (2006). Developing a pedagogy of teacher education: Understanding teaching and learning about teaching. London: Routledge. ISBN 978-0-415-36727-1

Loughran, J. J. (2010). What Expert Teachers Do. Abingdon, Oxford: Routledge. ISBN10: 0-20385147-1 (ebk)

Mayes, T., \& De Freitas, S. (2004). Review of e-learning theories, frameworks and models. JISC $e$ learning models desk study 1. 1-43 http://www.jisc.ac.uk/whatwedo/programmes/elearningpedagogy/outcomes.aspx

Ministry of Education (2007). The New Zealand Curriculum. Wellington, NZ: Author. ISBN 9780 790326153 
Pachler, N., Bachmair, B., \& Cook, J. (2010). Mobile Learning: Structures, agency, practices. New York, Dordrecht, Heidelberg, London: Springer. ISBN 978-1-4419-0585-7. 22 May. 2014 $<$ http://books.google.com/books?id=4wic3O1Sf0EC\&pg=PA161\&lpg=PA161\&dq=Pachler+e $\underline{\mathrm{t}+\mathrm{al} \& \text { source }=\mathrm{bl} \text { \&ots=Q EzHtPKH5\&sig=P-tS2cbbP2oGvdYL18GO7 XSgqo }}$

Pachler, N., Cook, J., \& Bachmair, B. (2010). Appropriation of mobile cultural resources for learning. International Journal of Mobile and Blended Learning, 2(1) 1-21 doi:10.4018/jmbl.201001010

Petit, J. \& Kukulska-Hume, A. (2007). Going with the grain: Mobile devices in practice. Australasian Journal of Educational Technology. 23(1), 17-33. http://www.ascilite.org.au/ajet/ajet23/pettit.html

Petrie, H.G. and Oshlag, R. (1993). Metaphor and learning. In, Andrew Ortony (Ed.) Metaphor and Thought (2nd edition), (Chapter 25, pp. 579-609). Cambridge UK: Cambridge University Press.

Ryan, M. E., \& Healy, A. H. (2009) It's not all about school: ways of disrupting pre-service teachers' perceptions of pedagogy and communication. Teaching and Teacher Education, 25(3). 424429. http://eprints.qut.edu.au/18436/1/c18436.pdf

Shulman, L. S. (1986). Those who understand: Knowledge growth in teaching. Educational Researcher, 15(2) 4-14

Vygotsky, L. S., \& Cole, M. (1978). Mind in society: The development of higher psychological processes. Cambridge: Harvard University Press.

Wilson, S., \& McChesney, J. (2013). Navigating and noticing: Preservice teachers' journeys in planning mathematics programmes. Curriculum Matters. 9. 102-119

Wright, N. (2011). mLearning in a New Zealand secondary school: A case study. The International Journal of Learning. 18(1), 575-587. ISSN 1447-9494

Note about the author

Noeline Wright spent 20 years teaching in secondary schools before embarking on a doctorate and becoming a teacher educator at the University of Waikato. There, she teaches part of an undergraduate paper, the secondary graduate cohort, and the Masters of Teaching and Learning. Her research interests tend to focus on the intersection of digital technologies and pedagogy in secondary school and ITE contexts. 